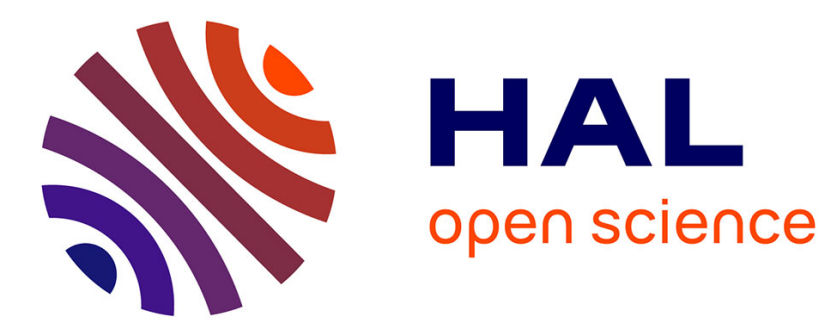

\title{
Stability analysis of a swirl spray combustor based on flame describing function
}

Clement Mirat, Daniel Durox, Thierry Schuller

\section{To cite this version:}

Clement Mirat, Daniel Durox, Thierry Schuller. Stability analysis of a swirl spray combustor based on flame describing function. Proceedings of the Combustion Institute, 2015, 35 (3), pp.3291-3298. 10.1016/j.proci.2014.08.020 . hal-01344933

\section{HAL Id: hal-01344933 \\ https://hal.science/hal-01344933}

Submitted on 28 Feb 2020

HAL is a multi-disciplinary open access archive for the deposit and dissemination of scientific research documents, whether they are published or not. The documents may come from teaching and research institutions in France or abroad, or from public or private research centers.
L'archive ouverte pluridisciplinaire HAL, est destinée au dépôt et à la diffusion de documents scientifiques de niveau recherche, publiés ou non, émanant des établissements d'enseignement et de recherche français ou étrangers, des laboratoires publics ou privés. 


\title{
Stability analysis of a swirl spray combustor based on flame describing function
}

\author{
C. Mirat ${ }^{\mathrm{a}, \mathrm{b}, *}$, D. Durox ${ }^{\mathrm{a}, \mathrm{b}}, \mathrm{T}$. Schuller ${ }^{\mathrm{a}, \mathrm{b}}$ \\ ${ }^{a}$ CNRS, UPR 288, Laboratoire d'Energétique Moléculaire et Macroscopique, Combustion (EM2C), \\ Grande Voie des Vignes, 92290 Châtenay-Malabry, France \\ ${ }^{b}$ Ecole Centrale Paris, Grande Voie des Vignes, 92290 Châtenay-Malabry, France
}

\begin{abstract}
Self-sustained combustion oscillations observed at limit cycles in a swirl combustor equipped with a series of steam assisted liquid fuel injectors are analyzed with the Flame Describing Function (FDF) framework. It is first shown that for globally fuel lean injection conditions, the spray flames investigated burn in a non-premixed mode. A nonsooty and a sooty regime are explored. Their frequency response to acoustic forcing is characterized by exploiting the $\mathrm{OH}^{*}$ chemiluminescence signal and a velocity signal measured by Laser Doppler velocimetry at the air injection unit outlet. It is found that the FDF of these non-premixed swirl spray flames features a distinct response compared to lean premixed swirl flames. The gain and phase lag of these FDF are both a strong function of the perturbation amplitude. At a fixed forcing frequency, the FDF phase lag increases with the perturbation level for the non-sooty flame investigated and it decreases for the sooty flame case. The sooty flame has also a much lower cut-off frequency for the FDF gain than the non-sooty flame. It is then shown that these features are essential to reproduce the correct instability bands and oscillation frequencies observed at limit cycles in the experiments. For the sooty flame, combustion is always found stable in agreement with the low cut-off frequency found for the FDF. A linear analysis for the non-sooty flame fails to capture the low frequency instabilities observed in the experiments that have the largest oscillation levels. Only the use of the FDF enables to reproduce the correct dynamical states observed in the combustor. It is further concluded that the $\mathrm{OH}^{*}$ chemiluminescence signal may safely be used to infer the frequency response of these non-premixed swirl spray flames at globally fuel lean injection conditions.
\end{abstract}

Keywords: Thermo-acoustic instabilities, Flame describing function, Liquid injection, Nonlinear flame dynamics, Spray flame, Swirled flame

\section{Introduction}

Like those operated with gaseous fuels, combustors fed by liquid fuels are prone to combustion instabilities triggered by the dynamics of the fuel [1-3] or air $[1,4,5]$ supply lines. To determine the stability margins of these non-premixed systems, it is useful to characterize the flame frequency response to external flow perturbations.

Analysis of the acoustic response of swirl spray flames remain relatively scarce. The first objective of this study is to complete these data over a broad range of excitation frequencies and amplitudes to reveal the main features of their frequency response to flow perturbations. The second one is to conduct a stability analysis

\footnotetext{
*Corresponding author: Clément Mirat, Laboratoire EM2C, Grande Voie des Vignes, 92290 Châtenay-Malabry, France

Email address: clement.mirat@ecp.fr (C. Mirat)
}

and compare predictions with measurements made during self-sustained instabilities at limit cycle in a generic combustor. This allows to examine if tools developed for perfectly premixed systems can safely be used to infer the thermo-acoustic state of combustors operated with non-premixed spray flames.

In many studies of the dynamics of spray flames, the analysis is restricted to the examination of the limit cycle of a self-sustained oscillation taking place in the combustion chamber where pressure and $\mathrm{OH}^{*}$ or $\mathrm{CH}^{*}$ flame chemiluminescence measurements are correlated with the spray dynamics during the instability $[3,5,6]$. Characterizations of the response of swirl spray flames to liquid fuel flowrate modulations were realized in a few laboratory scale experiments $[1,2,7]$. Yi and Santavicca [2] found that the frequency response of their flame is sensitive to air mass flowrate, equivalence ratio and air preheat temperature variations, but it is invariant 


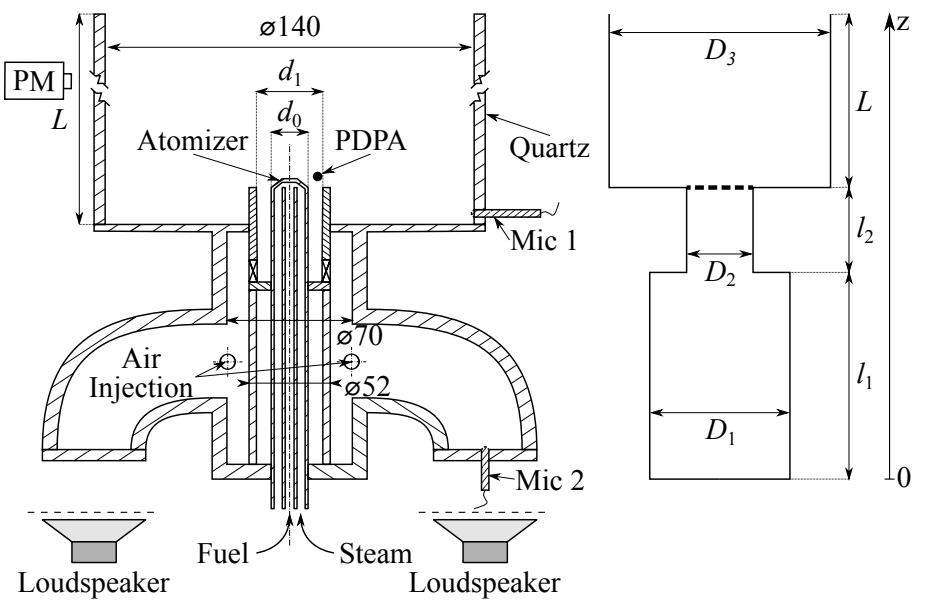

Figure 1: Schematic of the main elements of the multi-phase flow burner.

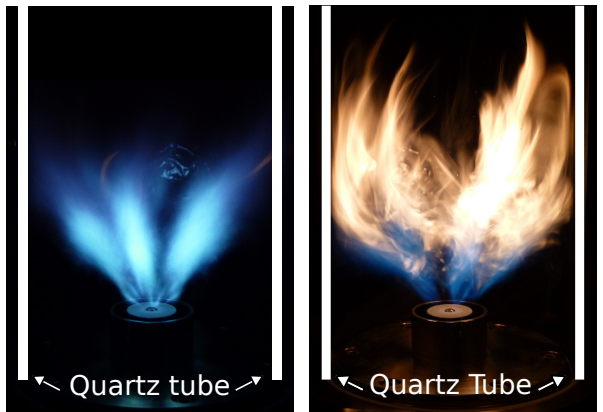

(a) Non-sooty flame

(b) Sooty flame

Figure 2: Images of the flame obtained for different fuel mass flow rates $\dot{m}_{f}=10.0 \mathrm{~g} \mathrm{~min}^{-1}$ (a) and $\dot{m}_{f}=$ $13.3 \mathrm{~g} \mathrm{~min}^{-1}$ (b). Gas-to-liquid ratio GLR $=0.07$, equivalence ratio $\phi=0.8$, swirl number $S=0.92$. to fuel modulation amplitude. For liquid fuel injectors featuring a large pressure drop, thermo-acoustic oscillations result from a resonant coupling with the air feeding line. Analysis of the response of swirl spray flames to air flowrate modulations are generally limited to a few specific forcing frequencies with a fixed amplitude $[1,4,8]$. It was demonstrated that the oscillation of the air flow leads to droplet clustering $[1,7,9]$ and equivalence ratio fluctuations [6]. The frequency response of swirl spray flames submitted to air flow rate modulations was however not characterized yet over a broad frequency range.

Effects of excitation amplitude of the air flow rate are rarely considered for spray flames, it is then interesting to examine the main features of the frequency response of non-fully premixed flames fed by gaseous fuels to flow oscillations. Hield and Brear [10] found that the time lag between pressure and heat release rate oscillations is a strong function of the root-mean-square value of the acoustic velocity fluctuations during unstable operation of their non-premixed combustor. In an analysis of the response of fuel stratified lean-premixed swirl flames submitted to acoustic excitations, Kim and Hochgreb [11] found that the phase lag between heat release rate and velocity disturbances is a strong function of the fuel stratification and perturbation amplitude. The same type of feature is observed for swirl flames submitted to equivalence ratio fluctuations [12]. It is then worth examining the response of spray flames to flow modulations at different input levels.

In this study, self-sustained combustion oscillations observed at limit cycles in a combustor with swirlstabilized spray flames are analyzed with the help of the flame describing function (FDF) [13]. The experimental setup is presented in section 2 . The structure of the swirl-stabilized spray flames investigated is presented in section 3. Self-sustained oscillations observed at limit cycles when the combustion chamber length is varied are examined in section 4 . The combustor acoustic response is determined in section 5 and the FDF of two different flames are analyzed in section 6 . These data are combined in section 7 to infer the system stability and compare results with experiments.

\section{Experimental setup}

The combustor is sketched in Fig. 1. It comprises a plenum, two loudspeakers (Monacor Number one, SPH135/AD, 60 W) which can be replaced by two rigid plates, a central cylindrical bluff body where a generic internal twin-fluid atomizer is installed [14], a radial swirler in the annular gap of the air injector and a cylindrical flame tube. This simplified configuration is used to stabilize spray flames in a swirl flow. Experiments are conducted at Reynolds numbers $R e=U_{b} d_{0} / v_{a}=$ 6500 to 9000 , where $U_{b}$ is the bulk flow velocity in the annular air injection channel of internal diameter $d_{0}=30 \mathrm{~mm}$ and external diameter $d_{1}=40 \mathrm{~mm}$, and $v_{a}$ is the air viscosity at temperature $T_{a}$. A preheated air flow is delivered to the plenum with a maximum mass flow rate $\dot{m}_{a}=200 \mathrm{~N} \mathrm{~L} \mathrm{~min}^{-1}$ regulated by a thermal mass flow controller at a temperature $T_{a}=443 \mathrm{~K}$. The rotation of the air flow is generated by a radial swirler with a swirl number $S=0.92$ that was measured at the burner outlet [15]. The combustion chamber is made of quartz allowing visualization of the flames in the near ultraviolet and visible ranges. It has a $140 \mathrm{~mm}$ internal diameter and a length $L=0.50 \mathrm{~m}$. The chamber length can be gradually augmented by adding metallic cylinders on the top of the quartz tube to reach a maximum length $L=1.22 \mathrm{~m}$. 
The fuel injector is an internal steam assisted atomizer fed by superheated steam at $T_{s}=423 \mathrm{~K}$ and dodecane at $T_{f}=413 \mathrm{~K}$. This unit is embedded in the thermalized cylindrical central bluff body shown in Fig. 1. Steam and dodecane are first mixed within the injector that operates at a few bars and the two-phase fluid mixture exhausts in the combustion chamber through five cylindrical injection holes with diameter $d_{n}=0.20 \mathrm{~mm}$ [14]. This atomizer generates a quasi-monodisperse jet spray with a constant value of the droplet Sauter mean diameter $(S M D)$ equal to $10 \mu \mathrm{m}$ above a certain threshold level of the steam to fuel mass ratio $G L R=\dot{m}_{s} / \dot{m}_{f} \geq$ 0.05 injected, where $\dot{m}_{s}$ and $\dot{m}_{f}$ denote the mass flow rates of steam and dodecane. These conditions were realized in these experiments, so that the dodecane sprays generated in the following experiments have the same $S M D$ of $10 \mu \mathrm{m}$ for all conditions explored.

The airflow is seeded with oil droplets with a $S M D$ equal to $3 \mu \mathrm{m}$ to measure the axial velocity $u_{z}$ of the air stream downstream the burner with a TSI Phase Doppler Particle Analyser (PDPA) system (Fig. 1). Velocity measurements are made at a distance $z=1.4 \mathrm{~mm}$ above the injection plane in the middle of the annular air injection section. It was checked that this additional injection of oil does not modify the flame shape and the chemiluminescence signal. The $\mathrm{OH}^{*}$ radiation from the flame is recorded with a photomultiplier Hamamatsu H578406 equipped with a $10 \mathrm{~nm}$ bandpass filter centered on $307.7 \mathrm{~nm}$ (Melles Griot F10-307.1-4-25.0M) with 20\% of maximum transmittance.

When the loudspeakers are replaced by rigid plates (Fig. 1), the combustor features various self-sustained thermo-acoustic oscillations depending on the combustion chamber length $L$ and the fuel and air mass flowrates injected. Two thermalized microphones (Brüel\&Kjær 2670), Mic 1 located in the chamber and Mic 2 located in the plenum are used to record the acoustic pressure. The velocity of the airflow at the injection tube outlet, the $\mathrm{OH}^{*}$ radiation of the flame and the acoustic pressures in the chamber and plenum are simultaneously recorded during unstable regimes.

\section{Flame structure}

The structure of the swirl-stabilized spray flames is first examined during stable operation of the combustor. Results are presented in terms of the fuel mass flowrate $\dot{m}_{f}$ and the global equivalence ratio of the injected reactants defined as $\phi=\left(\dot{m}_{f} / \dot{m}_{a}\right) / \alpha_{s}$, where $\alpha_{s}=0.066$ for stoichiometric combustion of dodecane.

Figure 2 shows two images of the light emission from the flame recorded with a camera equipped with a glass

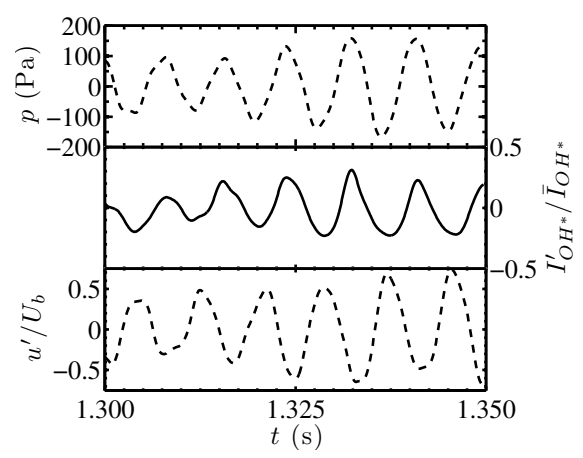

Figure 3: Acoustic pressure measured by Mic 1, relative $\mathrm{OH}^{*}$ chemiluminescence intensity and relative velocity $u^{\prime} / U_{b}$ fluctuation signals during a self-sustained oscillation reached for $L=1.13 \mathrm{~m}$, $\dot{m}_{f}=12.5 \mathrm{~g} \mathrm{~min}^{-1}, \phi=0.95, G L R=0.08, U_{b}=7.5 \mathrm{~m} \mathrm{~s}^{-1}$.

lens when the global equivalence ratio $\phi=0.8$ and the $G L R=0.07$ are kept constant. Figure 2(a) obtained for a fuel mass flow rate $\dot{m}_{f}=10.0 \mathrm{~g} \mathrm{~min}^{-1}$ shows an essentially non-sooty blue flame with five reacting jets stabilized around the five jet sprays generated by the atomizer. It is important to note that combustion takes place in this case away from the quartz tube and can be considered complete. The spray and the flame strongly interact with the quartz tube in Fig. 2(b) obtained for a higher fuel mass flow rate $\dot{m}_{f}=13.3 \mathrm{~g} \mathrm{~min}^{-1}$. The intense yellow emission from the flame tip is due to soot production. Incomplete combustion is caused in this regime by a slow evaporation/mixing of the fuel spray creating locally fuel rich zones due to an overall drop of the temperature in the proximity of the quartz wall.

\section{Combustion instability}

Signals at limit cycles of unstable modes are now examined. Figure 3 shows the time evolution of the acoustic pressure in the chamber, the velocity fluctuation at the air injection outlet and the relative $\mathrm{OH}^{*}$ chemiluminescence intensity fluctuation during $50 \mathrm{~ms}$ when the conditions are set to $\dot{m}_{f}=12.5 \mathrm{~g} \mathrm{~min}^{-1}, \phi=0.95$, $G L R=0.08$ for a chamber length $L=1.13 \mathrm{~m}$. In this configuration, the mean flame structure is similar to that shown in Fig. 2(a) (non-sooty flame), but the system features a self-sustained thermo-acoustic instability. The pressure, velocity and chemiluminescence signals feature large amplitude oscillations at the frequency of $120 \mathrm{~Hz}$. The amplitude of the pressure fluctuation close to the chamber dump plane reaches $150 \mathrm{~Pa}$. The velocity fluctuation level is about $50 \%$ and the relative $\mathrm{OH}^{*}$ fluctuation level is about $20 \%$. These two last signals are in this case out of phase by $\pi$, but the pressure and the chemiluminescence signals are in phase and the Rayleigh criterion is satisfied. 
Table 1: Stability map as a function of the chamber length $L$ and the global equivalence ratio $\phi$ when $\dot{m}_{f}=12.5 \mathrm{~g} \mathrm{~min}^{-1}$. Crosses $\mathrm{X}$ denote stable cases. The oscillation frequency at limit cycle is indicated for unstable cases.

\begin{tabular}{|c|c|c|c|c|c|c|}
\hline$L(\mathrm{~mm})$ & 68 & 77 & 83 & 103 & 113 & 122 \\
\hline$\phi=0.95 f(\mathrm{~Hz})$ & $\mathrm{x}$ & 174 & 168 & 131 & 120 & 118 \\
\hline$\phi=0.75 f(\mathrm{~Hz})$ & $\mathrm{x}$ & $\mathrm{x}$ & $\mathrm{x}$ & $\mathrm{x}$ & $\mathrm{x}$ & $\mathrm{x}$ \\
\hline
\end{tabular}

Table 1 shows the thermo-acoustic state of the system for the different configurations analyzed as a function of the chamber length $L$ and equivalence ratio $\phi$ when the fuel mass flow rate is fixed to $\dot{m}_{f}=12.5 \mathrm{~g} \mathrm{~min}^{-1}$. The $\mathrm{X}$ crosses denote stable regimes. For the unstable cases, the frequency at limit cycle is indicated.

When $\phi=0.75$, the flame extends along the quartz wall as in Fig. 2(b) (sooty-flame), and the system is stable for all combustion chamber lengths explored. When the global equivalence ratio is set to $\phi=0.95$, the flame shape and luminosity are similar to that shown in Fig. 2(a) (non-sooty flame). The system becomes in this case unstable for chamber lengths longer than $L \geq 0.77 \mathrm{~m}$ and the instability frequency decreases when the length $L$ increases.

\section{Acoustic analysis of the combustor}

A modal analysis of the combustor without combustion is carried out by replacing the rigid plates with the loudspeakers to determine the eigenfrequencies of the system (Fig. 1). These experiments are conducted for a combustion chamber length $L=1.13 \mathrm{~m}$. An air mass flow rate $\dot{m}_{a}=100 \mathrm{NL} \mathrm{min}^{-1}$ is injected at a temperature $T_{a}=293 \mathrm{~K}$ and the acoustic forcing covers the frequency range from $0 \mathrm{~Hz}$ to $450 \mathrm{~Hz}$ with a constant sound level.

Figure 4 shows the response measured by Mic 1 and Mic 2 as a function of the forcing frequency. The response in the chamber features two main peaks at the frequencies $f_{1}=82 \mathrm{~Hz}, f=222 \mathrm{~Hz}$ and a small additional peak at $f=370 \mathrm{~Hz}$. The response in the plenum comprises three peaks at frequencies $f_{1}=82 \mathrm{~Hz}, f_{2}=$ $136 \mathrm{~Hz}$ and $f=330 \mathrm{~Hz}$. The first mode identified at $f_{1}$ has a quarter wavelength structure between the plenum inlet and the outlet of the combustion chamber (See Fig. 5). The second peak in the plenum, at $f_{2}=136 \mathrm{~Hz}$, does not appear in the chamber response.

The structure of this mode is similar to the three quarter wave mode established between the plenum inlet and the outlet of the chamber (see Fig. 5). In this mode, Mic 1 lies close to the pressure node, which explains the small amplitude of the response detected in the chamber. The higher modes are not discussed here since they

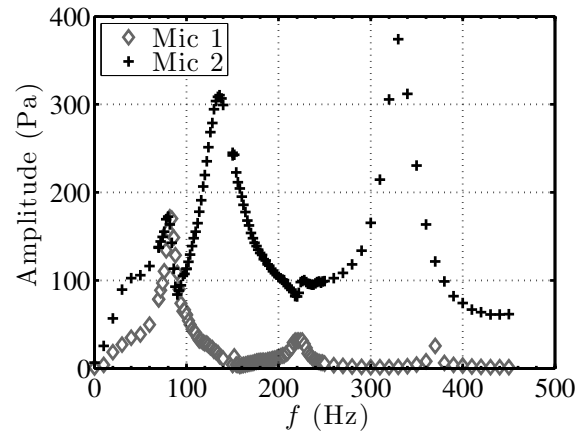

Figure 4: Pressure amplitude distributions measured by Mic 1 and Mic 2 as a function of the forcing frequency $f$ for $L=1.13 \mathrm{~m}$.

are too far from the observed instability frequency for this combustor length.

A one dimensional low-order acoustic model is now used with three coupled cavities to simulate the acoustic response of the combustor $[16,17]$. This idealized model is shown in Fig. 1 where $l_{1}=200 \mathrm{~mm}, D_{1}=$ $110 \mathrm{~mm}, l_{2}=55 \mathrm{~mm}, D_{2}=26 \mathrm{~mm}$ and $D_{3}=140 \mathrm{~mm}$. The boundary conditions correspond to a pressure antinode at the plenum inlet and to a pressure node at the combustion chamber outlet. Acoustic radiation at the chamber outlet is treated with an end correction by increasing the length $L$ by $0.4 D_{3}$ [18]. The evolution of the eigenfrequencies of the two first modes of this coupled cavity model are shown in Fig. 6 when the combustion chamber length $L$ is varied. These predictions are in fairly good agreement with the peak frequencies measured in the combustor during the acoustic characterization at ambient temperature (grey symbols in Fig. 6).

Calculations with the combustion chamber cavity filled with hot gases are now examined. In the model, the gas temperatures are set to $T_{1}=T_{2}=443 \mathrm{~K}$ in the plenum and injection cavities and to $T_{3}=1200 \mathrm{~K}$ for the burnt gases in the chamber. These values correspond to mean quantities that were measured in the experiment. The corresponding eigenfrequencies for the

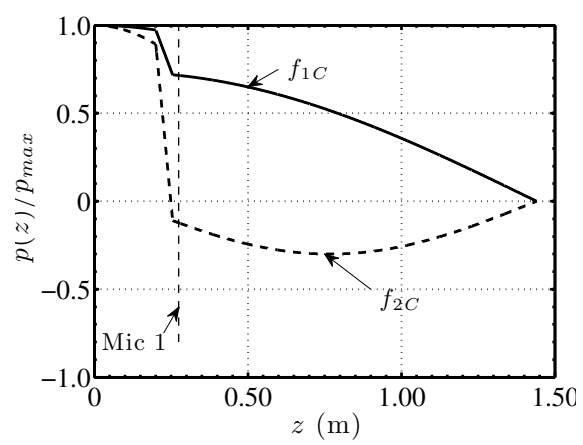

Figure 5: Acoustic pressure distribution in the model system for the two first modes for $L=1.13 \mathrm{~m}$ at ambient temperature. 


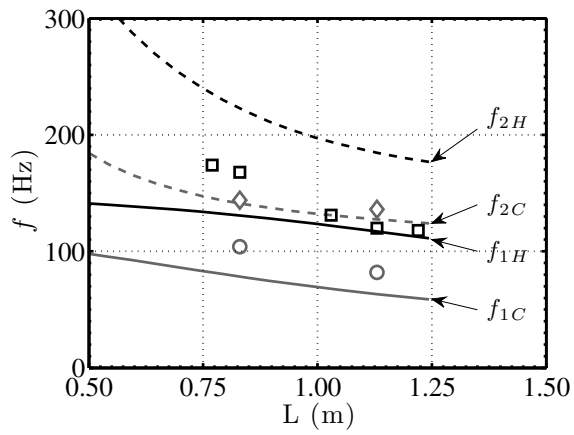

Figure 6: Evolution of the acoustic eigenfrequencies as a function of the combustion chamber length $L$ for the two first modes of the system. Grey lines: calculations at ambient temperature. Black Lines : calculations with hot gases in the chamber without unsteady flame. Grey symbols represent the two first measured frequencies $f_{1}(\circ)$ and $f_{2}(\diamond)$ during the acoustic characterization at ambient temperature. Square black symbols represent the instability frequencies detected at limit cycle.

two first modes are shown as black lines in Fig. 6. These predictions are compared to the frequencies measured at limit cycles in the unstable configurations (Tab. 1) represented by square symbols in Fig. 6.

This analysis indicates that the limit cycles of the instability set around the first acoustic mode of the system. When $L \geq 1 \mathrm{~m}$ the instability frequency is locked on the first acoustic mode. When $L<1 \mathrm{~m}$, the limit cycle instability frequency takes a slightly higher value than the acoustic mode. This type of shift of the instability frequency with respect to the acoustic mode is often observed $[13,16]$ and results from the flame response [19].

\section{Flame describing function}

The flame frequency response to flow perturbations is now analyzed when the combustion chamber length is set to $L=0.30 \mathrm{~m}$. The system is in this case free of instability, a condition which is required to safely measure the FDF. The spray flame responses are examined when the airflow is modulated acoustically by the two loudspeakers with a maximum power of $60 \mathrm{~W}$ (see Fig. 1). Using a set of quasi-steady experiments, it was first shown that the $\mathrm{OH}^{*}$ flame chemiluminescence intensity is proportional to the heat release rate for the globally fuel lean flames investigated, i.e. when $\phi<1$ [15]. By moving the photomultiplier around the burner, it was also checked that the signal recorded does not depend on the location of this device. It is thus assumed that the fluctuations of the $\mathrm{OH}^{*}$ intensity recorded by this detector is a good tracer of the global heat release rate fluctuation.

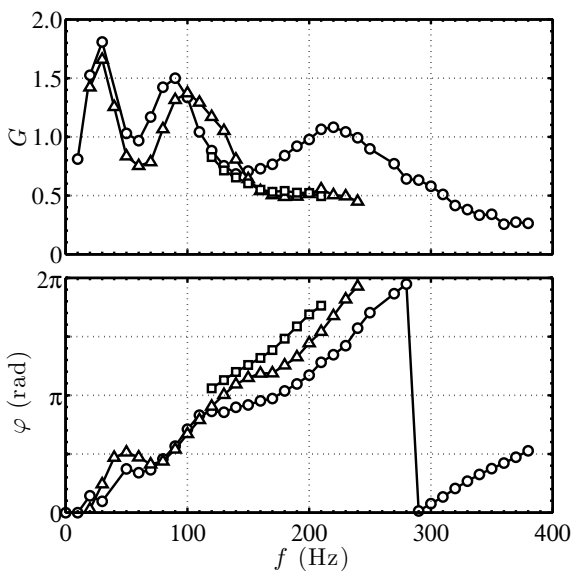

Figure 7: Gain $G$ and phase lag $\varphi$ of the FDF as a function of frequency and input level. Non-sooty flame case: $\dot{m}_{f}=12.5 \mathrm{~g} \mathrm{~min}^{-1}$, $\phi=0.95, G L R=0.09, U_{b}=7.5 \mathrm{~m} \mathrm{~s}^{-1} . u^{\prime}$ corresponds to the root-mean-square value of the signal measured by PDPA and $U_{b}$ is the bulk velocity within the air injection unit. $\circ: u^{\prime} / U_{b}=0.09$, $\triangle: u^{\prime} / U_{b}=0.27$ and $\square: u^{\prime} / U_{b}=0.55$

Harmonic flow modulations at different amplitudes $u^{\prime} / U_{b}$, where $U_{b}$ denotes the bulk velocity in the air injection tube and $u^{\prime}$ is the root-mean-square value deduced from the PDPA signal, are produced at the burner outlet with the loudspeakers. The FDF is defined in the complex domain in terms of a gain $G$ and a phase $\varphi$ $[13,16,20,21]$ :

$$
\mathcal{F}\left(f, u^{\prime} / U_{b}\right)=\frac{\tilde{I} / \bar{I}}{\tilde{u} / U_{b}}=G\left(f, u^{\prime} / U_{b}\right) e^{i \varphi\left(f, u^{\prime} / U_{b}\right)}(1)
$$

where $\bar{I}$ is the mean value of $\mathrm{OH}^{*}$ intensity, $\tilde{I}$ and $\tilde{u}$ correspond to the Fourier components of the $\mathrm{OH}^{*}$ and velocity signals examined at the forcing frequency $f$. The gain $G$ and the phase lag $\varphi$ of the FDF are deduced in the experiments from the cross and power-spectral densities of the velocity and chemiluminescence signals examined at the forcing frequency for each amplitude $u^{\prime} / U_{b}$.

Measurements are made for the operating conditions explored in section 4 when the fuel mass flowrate is fixed to $\dot{m}_{f}=12.5 \mathrm{~g} \mathrm{~min}^{-1}$ and air is preheated to $T_{a}=443 \mathrm{~K}$. Figure 7 shows the gain and the phase of the measured FDF for the non-sooty flame obtained for an equivalence ratio $\phi=0.95$ with a bulk air injection velocity $U_{b}=7.5 \mathrm{~m} \mathrm{~s}^{-1}$. Excitation frequencies range from $10 \mathrm{~Hz}$ to $390 \mathrm{~Hz}$ for the input level $u^{\prime} / U_{b}=0.09$. They vary from $20 \mathrm{~Hz}$ to $230 \mathrm{~Hz}$ when $u^{\prime} / U_{b}=0.27$, and the exploration is limited from $120 \mathrm{~Hz}$ to $210 \mathrm{~Hz}$ when $u^{\prime} / U_{b}=0.55$. These limits are mainly due to limitations of the loudspeaker efficiency and to avoid destabilization of the mean flame at high forcing amplitude. 


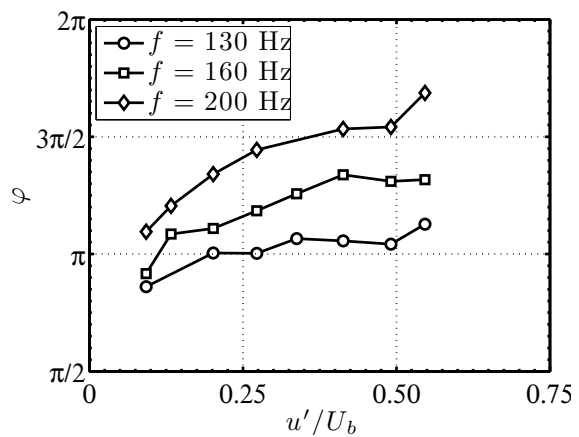

Figure 8: Zoom of the FDF phase lag as a function of the input level $u^{\prime} / U_{b}$ for three different frequencies. $\dot{m}_{f}=12.5 \mathrm{~g} \mathrm{~min}^{-1}, \phi=0.95$, $G L R=0.09, U_{b}=7.5 \mathrm{~m} \mathrm{~s}^{-1}$.

The evolution of the gain with the frequency is typical of that observed for swirl flames fed by gaseous fuels with several humps indicating possible inference mechanisms [22-24]. In the frequency range $100 \mathrm{~Hz}$ to $150 \mathrm{~Hz}$, the gain first increases with the perturbation amplitude before decreasing at higher amplitudes. It smoothly decreases at high amplitude for $f>150 \mathrm{~Hz}$ as for premixed flames.

The phase lag $\varphi$ increases regularly from 0 to $5 \pi / 2$ rad with the frequency, but it also increases with the modulation level. This feature contrasts with the FDF of perfectly premixed swirl flames for which it is generally found that the phase lag is weakly sensitive to the forcing amplitude [21, 22, 25]. This has several consequences for the stability margins of the combustor [13].

This point is further examined in Fig. 8 showing the evolution of the FDF phase lag when the amplitude $u^{\prime} / U_{b}$ increases for three different forcing frequencies within the range of frequencies where the system feature instabilities (see Tab. 1). The phase difference between an excitation at $u^{\prime} / U_{b}=0.09$ and the largest one at $u^{\prime} / U_{b}=0.48$ is larger than $\pi / 2$ for the frequency $f=200 \mathrm{~Hz}$. This observation indicates that the time lag needed by the perturbations to reach the flame front strongly depends on the modulation level in these spray flames. This type of feature has already been observed for the FDF of fully premixed laminar conical flames [13], but these flames do not share the same flame topology as the swirl flames investigated here. The response of swirl flames to equivalence ratio fluctuations [12] and of partially premixed swirl flames featuring different fuel stratifications to air flowrate modulations [11] share the same type of feature for the FDF phase lag. This indicates that fuel stratification and equivalence ratio fluctuations might be at the origin of this behavior in these spray flames. Periodic droplet clustering [1, 7, 9] might cause this in-homogenous

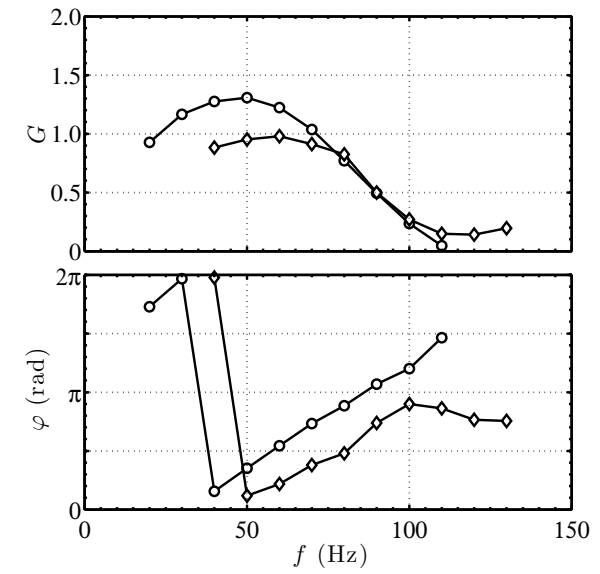

Figure 9: Gain $G$ and phase $\operatorname{lag} \varphi$ of the FDF as a function of the frequency and the input level. Sooty flame case: $\dot{m}_{f}=12.5 \mathrm{~g} \mathrm{~min}^{-1}$, $\phi=0.75, G L R=0.10, U_{b}=9.5 \mathrm{~m} \mathrm{~s}^{-1}$. The velocity $u^{\prime}$ corresponds to the root-mean-square value of the fluctuation amplitude measured by PDPA and $U_{b}$ is the bulk flow velocity in the air injection unit. $\circ: u^{\prime} / U_{b}=0.09$ and $\diamond: u^{\prime} / U_{b}=0.20$

distribution of fuel vapor in space and time. A more detailed analysis of the spray dynamics is necessary to verify this scenario, which is out of scope of this study.

Figure 9 shows the FDF gain and phase lag evolutions for two amplitudes $u^{\prime} / U_{b}=0.09$ and 0.20 when the global equivalence ratio is set to $\phi=0.75$, by increasing the air bulk injection velocity to $U_{b}=9.5 \mathrm{~m} \mathrm{~s}^{-1}$. These conditions lead to a sooty flame with a long tip impinging the quartz tube as in Fig. 2(b). The FDF is determined here for forcing frequencies varying from $20 \mathrm{~Hz}$ to $130 \mathrm{~Hz}$. It was checked that the $\mathrm{UV} \mathrm{OH}^{*}$ emission signal is not perturbed by the thermal radiation from soots. The FDF gain of this flame has a much lower cut-off frequency compared to the FDF of the non-sooty flame shown in Fig. 7. The gain approaches $G \approx 1$ at low-frequency. The cut-off frequency defined for $G=0.5$ is reached when $f=90 \mathrm{~Hz}$ and there is no response for $f \geq 110 \mathrm{~Hz}$. The gain decreases when the perturbation amplitude increases for the two amplitudes investigated. The phase lag $\varphi$ increases linearly with the frequency below $100 \mathrm{~Hz}$, but it was more difficult to gather experimental data at very low frequency with a good signal-to-noise ratio. The quasi-steady response of this flame is more difficult to capture accurately and the situation is more difficult to interpret than for the shorter non-sooty flame obtained for $\phi=0.95$. The phase lag now decreases drastically when the forcing amplitude increases. This response differs thus from the FDF shown in Fig. 7, but the phase lag still remains a strong function of the perturbation amplitude. The reason for this particular behavior of the FDF phase lag of 


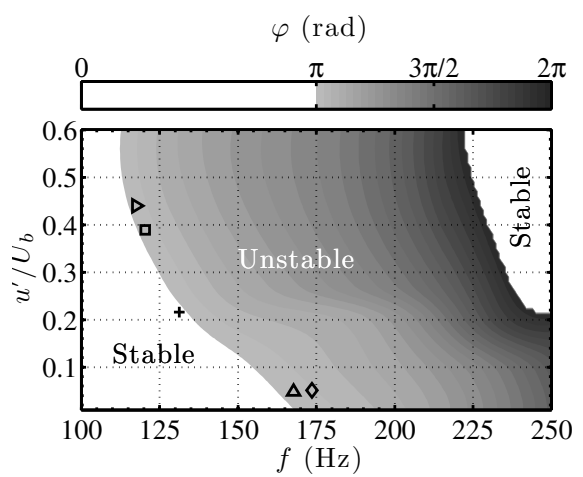

Figure 10: Instability band for the first mode based on the FDF shown in Fig. 7 as a function of the frequency $f$ and amplitude $u^{\prime} / U_{b}$. Symbols represent the phase lag deduced from the experiments at limit cycles : $\diamond: \varphi=1.03 \pi(L=0.77 \mathrm{~m}), \Delta: \varphi=1.02 \pi(L=0.83 \mathrm{~m})$, $+: \varphi=\pi(L=1.03 \mathrm{~m}), \square: \varphi=1.12 \pi(L=1.13 \mathrm{~m})$ and $\triangleright: \varphi=1.05 \pi(L=1.22 \mathrm{~m})$.

this sooty flame was not elucidated, but this feature was found reproducible for other cases tested.

\section{Stability analysis of the combustor}

The acoustic model from section 5 and FDF measurements from section 6 are now combined to analyze the thermo-acoustic stability of the combustor.

The easiest case to interpret is the stability of the system observed for the sooty flame when $\phi=0.75$. This configuration is stable for all tube lengths tested in this study (Tab. 1), because the gain of the FDF drops very quickly and vanishes for frequencies higher than $100 \mathrm{~Hz}$ (Fig. 9), while the lowest eigenmode of the combustor has a frequency $f_{1 H}$ higher than $100 \mathrm{~Hz}$ (Fig. 6).

Results are now analyzed for the non-sooty flame when $\phi=0.95$. Figure 6 indicates that the instability frequencies are located in the vicinity of the first acoustic mode $f_{1 H}$ calculated at hot conditions. The structure of this mode is close to that of a quarter wave mode of the global system (Fig. 5). The associated unstable regimes are thus delimited by the condition $\pi \leq \varphi(\tilde{u}, \tilde{I}) \leq 2 \pi$ for the FDF phase lag [26].

Figure 10 shows in grey scale the phase lag $\varphi$ in the range $\pi$ to $2 \pi$ interpolated with data from the FDF shown in Fig. 7, as a function of the frequency $f$ and amplitude $u^{\prime} / U_{b}$ of the oscillation. The grey region delineates the unstable band for the first mode $f_{1 H}$ of the system featuring a quarter wave like structure. This figure shows that this instability band strongly depends on the oscillation amplitude. The mode becomes unstable at a frequency of about $170 \mathrm{~Hz}$ for all perturbation amplitudes $u^{\prime} / U_{b} \geq 0.01$. Symbols represent the measured oscillation frequencies and amplitudes of instabilities observed at limit cycles. For $L=0.77 \mathrm{~m}$ and
$L=0.83 \mathrm{~m}$, the system is unstable with limited oscillation amplitudes of $u^{\prime} / U_{b} \simeq 0.05$ at a frequency close to $f=170 \mathrm{~Hz}$ as indicated by the vertical triangle and the diamond symbols in Fig. 10.

For longer combustion chamber lengths $L$ corresponding to lower acoustic resonant frequencies $f_{1 H}$, a linear stability analysis conducted with a flame transfer function measured for a small perturbation level $u^{\prime} / U_{b} \geq 0.20$ cannot capture the observed instabilities. The right triangle, square and cross symbols in Fig. 10 correspond to self-sustained oscillations observed in the combustor with the largest amplitudes $u^{\prime} / U_{b}>0.2$. Their oscillation frequencies lie outside the predicted instability band for small values of $u^{\prime} / U_{b}$, but this band shifts to lower frequencies as the oscillation level increases. These large oscillations at low frequency result from the change of the FDF phase lag with the amplitude. To explain these instabilities at low frequency, it is necessary to take into account the amplitude dependent frequency response of the flame. It can be noted that for the five unstable configurations, the phase lag measured at limit cycle always lies close to $\pi$, indicating that the amplitude of the oscillations reached at limit cycle of these instabilities is controlled by changes of the FDF phase lag $\varphi$ [13] and not by a drop of the FDF gain or increase of damping as suggested in several studies [25].

\section{Conclusion}

A stability analysis of a combustor operated with spray flames stabilized in a swirl flow has been carried out with a liquid fuel injection system. It was observed that combustion can be stable or unstable depending on the length of the combustion chamber and the flow operating conditions. The stability domain has been delineated for two types of flame at globally fuel lean injection conditions. The first one is a non-sooty blue flame and the second one is a sooty yellow flame impinging the combustor wall. It has been found that selfsustained instabilities occur only with the non-sooty flame. To explain the thermo-acoustic oscillations observed in the combustor, an acoustic analysis was combined with measurements of the frequency response of the two flames to air flow rate modulations.

It was found that the dynamics of these swirl spray flames is very sensitive to the velocity modulation amplitude and in particular the phase lag between velocity and heat release rate fluctuations is a strong function of the perturbation amplitude. The flame describing function of these flames has been integrated into an acoustic coupled cavity model to predict the thermo-acoustic state of the system. Results show that predictions are 
in good agreement with experimental data. For relatively long combustion chamber lengths, changes of the phase lag of the flame describing function with the perturbation amplitude fully explain the low frequencies and large oscillation amplitudes reached by the instability at limit cycle.

This study also demonstrates that the $\mathrm{OH}^{*}$ chemiluminescence signal can be used to infer the thermoacoustic stability of combustors operated with spray flames. Fluctuations of the $\mathrm{OH}^{*}$ signal were shown to be a good tracer of relative heat release rate disturbances at globally fuel lean injection conditions, even in the case of sooty flames.

\section{Acknowledgment}

This work is a collaboration between EM2C laboratory and EDF R\&D under contract with EDF / CRSA number 5910072747. We would like to thank the technical staff of the EM2C laboratory and particularly J. Beaunier, E. Jean-Bart and Y. Le Teno.

\section{References}

[1] F. Giuliani, P. Gajan, O. Diers, M. Ledoux, Proceedings of the Combustion Institute 29 (2002) 91-98.

[2] T. Yi, D. A. Santavicca, Journal of Propulsion and Power 25 (2009) 1259-1271.

[3] T. Yi, D. A. Santavicca, Journal of Propulsion and Power 28 (2012) 1000-1014.

[4] P. Gajan, A. Strzelecki, B. Platet, R. Lecourt, F. Giuliani, Journal of propulsion and power 23 (2007) 390-397.

[5] T. Providakis, L. Zimmer, P. Scouflaire, S. Ducruix, Journal of Engineering for Gas Turbines and Power 134 (2012) 111503.

[6] J. Eckstein, E. Freitag, C. Hisrch, T. Sattelmayer, Journal of Engineering for Gas Turbines and Power 128 (2006) 264-270.

[7] W.A. Chishty, Effects of thermoacoustic oscillations on spray combustion dynamics with implications for lean direct injection systems, Ph.D. Thesis, Virginia Polytechnic Institute and State University, USA, 2005.

[8] E. Haile, O. Delabroy, F. Lacas, D. Veynante, S. Candel, Symposium (International) on Combustion 26 (1996) 1663-1670.

[9] K. Gurubaran, R.I. Sujith, International Journal of Spray and Combustion Dynamics 3 (2011) 1-22.

[10] P. A. Hield, M. J. Brear, S. H. Jin, Combustion and Flame 156 (2009) 1683-1697.

[11] K. T. Kim, S. Hochgreb, Combustion and Flame 158 (2011) 2482-2499.

[12] K.T. Kim, J.G. Lee, B.D. Quay, D.A. Santavicca, Journal of Engineering for Gas turbine and Power 133 (2011) 021502.

[13] N. Noiray, D. Durox, T. Schuller, S. Candel, Journal of Fluid Mechanics 615 (2008) 139.

[14] C. Mirat, D. Durox, T. Schuller, in: ILASS-Europe, 2013, Chania, Crete, pp. 1-8.

[15] C. Mirat, D. Durox, T. Schuller, in: ASME Turbo Expo, 2014, Düsseldorf, Germany, GT2014-25111.

[16] P. Palies, D. Durox, T. Schuller, S. Candel, Combustion and Flame 158 (2011) 1980-1991.
[17] T. Poinsot, D. Veynante, Theoretical and numerical combustion, 2005.

[18] S. W. Rienstra, A. Hirschberg, An Introduction to Acoustics, April, Eindhoven University of Technology, 2011.

[19] C. Silva, F. Nicoud, T. Schuller, D. Durox, S. Candel, Combustion and Flame 160 (2013) 1743-1754.

[20] D. Durox, T. Schuller, N. Noiray, S. Candel, Proceedings of the Combustion Institute 32 (2009) 1391-1398.

[21] B. Cosic, J.P. Moeck, C.O. Paschereit, Combustion Science and Technology 186 (2014) 713-736.

[22] P. Palies, D. Durox, T. Schuller, S. Candel, Combustion and Flame 157 (2010) 1698-1717.

[23] S. Schimek, J. P. Moeck, C. O. Paschereit, Journal of Engineering for Gas Turbines and Power 133 (2011) 101502.

[24] K.T. Kim, D.A. Santavicca, Combustion Science and Technology 185 (2013) 999-1015.

[25] T. Lieuwen, Unsteady Combustor Physics, Cambridge University Press, 2012.

[26] D. Durox, J. P. Moeck, J.-F. Bourgouin, P. Morenton, M. Viallon, T. Schuller, S. Candel, Combustion and Flame 160 (2013) 1729-1742. 